OPEN ACCESS

Edited by:

Tadashi Kimura,

Osaka University Hospital, Japan

Reviewed by:

Seido Takae,

St. Marianna University School of

Medicine, Japan

Alessandro Conforti, Università degli Studi di Napoli

Federico II, Italy

*Correspondence:

Dilly O. C. Anumba

d.o.c.anumba@sheffield.ac.uk

Specialty section:

This article was submitted to Reproduction

a section of the journal

Frontiers in Endocrinology

Received: 31 May 2018 Accepted: 05 September 2018 Published: 24 September 2018

Citation:

Amabebe E and Anumba DOC (2018) Psychosocial Stress, Cortisol Levels, and Maintenance of Vaginal Health

Front. Endocrinol. 9:568.

doi: 10.3389/fendo.2018.00568

\section{Psychosocial Stress, Cortisol Levels, and Maintenance of Vaginal Health}

\author{
Emmanuel Amabebe and Dilly O. C. Anumba* \\ Academic Unit of Reproductive and Developmental Medicine, University of Sheffield, Sheffield, United Kingdom
}

Stress stimuli are ubiquitous and women do not enjoy any exemptions. The physiologic "fight-or-flight" response may be deleterious to the female lower genital tract microbiome if the stress stimuli persist for longer than necessary. Persistent exposure to psychosocial stress and stimulation of the hypothalamic-pituitary-adrenal (HPA) and sympathetic-adrenal-medullary (SAM) axes, and associated hormones are risk factors for several infections including genitourinary tract infections. Though this could be due to a dysregulated immune response, a cortisol-induced inhibition of vaginal glycogen deposition may be involved especially in the instance of vaginal infection. The estrogen-related increased vaginal glycogen and epithelial maturation are required for the maintenance of a healthy vaginal ecosystem (eubiosis). The ability of cortisol to disrupt this process as indicated in animal models is important in the pathogenesis of vaginal dysbiosis and the subsequent development of infection and inflammation. This phenomenon may be more crucial in pregnancy where a healthy Lactobacillus-dominated vaginal microbiota is sacrosanct, and there is local production of more corticotropin-releasing hormone $(\mathrm{CRH})$ from the decidua, fetal membranes and placenta. To highlight the relationship between the stress hormone cortisol and the vaginal microbiomial architecture and function, the potential role of cortisol in the maintenance of vaginal health is examined.

Keywords: stress, corticotropin-releasing hormone, cortisol, estrogen, vaginal microbiome, vaginal microbiota

\section{INTRODUCTION}

Stress is an organism's attempt to adequately respond to either internal or external threats or injuries. It refers to any physical or psychological challenge that threatens or has the potential of threatening the equilibrium of an organism's internal milieu (homeostasis) (1-3). Such challenges could be life events, situations, emotive feelings, and interactions that adversely affect the individual's wellbeing or trigger perceived harmful responses. Psychosocial stress stimuli comprise life experiences that include changes in personal life and relationships, occupation, housing, family composition, and domestic violence necessitating adaptive survival behaviors/responses from the affected individual $(4,5)$. Stress stimulates the hypothalamic-pituitary-adrenal (HPA) axis, which eventually leads to elevated levels of cortisol. As a downstream effector of the stress-induced neuroendocrine response, cortisol exerts global effects in the body to maintain homeostasis and enhance the organism's capacity to respond to and grapple with physical and emotional stresses (6). For instance, it primes the organism for "fight or flight" by promoting energy metabolism via glycogenolysis, gluconeogenesis, proteolysis and lipolysis, as well as regulates several immune and inflammatory responses (7). Furthermore, it increases blood pressure, has diverse bone effects, elicits both positive and negative effects on cell growth, and facilitates apoptosis in certain cell types, 
including certain neuronal cells (8). Normal immune function may be impaired or dysregulated by exposure to chronic stress through the HPA axis and the sympathetic-adrenal-medullary (SAM) axis, resulting in the chronic production of glucocorticoid hormones and catecholamines (9)

Cortisol is a steroid (glucocorticoid) hormone produced by the zona fasciculata of the adrenal cortex within the adrenal gland. It is released by the adrenal glands as part of the fight-or-flight mechanism in response to stress or fear, but has been described as public health's foremost enemy (10). Its functions include the modulation of increased blood sugar through gluconeogenesis and induction of insulin resistance $(11,12)$, metabolism of fat, protein, and carbohydrates, growth and reproduction, immune suppression (13), sodium-potassium transport $(14,15)$, cognition and memory $(13,16)$, and the regulation of bone formation (17).

The release of cortisol is regulated by the HPA axis via the secretion of corticotropin-releasing hormone (CRH) by the paraventricular nucleus (PVN) of the hypothalamus, which stimulates corticotrophs in the anterior pituitary to secrete adrenocorticotropic hormone (ACTH, corticotropin), which travels through the bloodstream to the adrenal cortex. ACTH stimulates the synthesis of cortisol and other glucocorticoids. Cortisol ultimately inhibits the HPA neuroendocrine response via a negative feedback mechanism to restore a steady state $(13,18)$. Cortisol has a circadian rhythm with lowest levels at midnight and peak levels ( $\sim 399 \mathrm{nmol} / \mathrm{l})$ in the morning (around 8:30) (19).

Hitherto, most studies have attributed the pathogenesis of stress-related vaginal dysbiosis solely to impaired immune function and loss of Lactobacillus species dominance $(9,20)$, while others have merely enumerated the use of corticosteroids as a factor associated with Bacterial vaginosis (BV). However, the mechanisms by which cortisol, the classical stress hormone, modulates the estrogen-induced deposition and accumulation of glycogen in the vaginal epithelium and the implications for maintenance of vaginal homeostasis has received little attention. Due to the importance of the association between vaginal glycogen, Lactobacillus species dominance and low $\mathrm{pH}$ for the reproductive health of women, i.e., reducing the risk of sexually transmitted infections (STIs), BV, and preterm labor (21), this review examines the vaginal glycogen response induced by estrogen and the potential repressive role of cortisol.

\section{Literature Search}

With the use of words and phrases including (but not limited to) "stress and vaginal health," "stress and bacterial vaginosis," "stress and vaginal infection," "stress and immune function," "stress and vaginal Lactobacilli," "stress, infection and preterm

\footnotetext{
Abbreviations: ACTH, adrenocorticotropic hormone; BV, bacterial vaginosis; cAMP, cyclic adenosine monophosphate; CCL5, Chemokine (C-C motif) ligand 5; CRH, corticotropin-releasing hormone; DES, diethylstilboestrol; HPA, hypothalamic-pituitary-adrenal; IFN $\gamma$, interferon gamma; IL, interleukin; IL1RA, interleukin-1 receptor antagonist; NF-кB, nuclear factor kappa-lightchain-enhancer of activated B cells; NGAL, neutrophil gelatinase-associated lipocalin; PVN, paraventricular nucleus; SAM, sympathetic-adrenal-medullary; SLPI, secretory leucocyte protease inhibitor; TLR, toll-like receptors; TNF- $\alpha$, tumor necrosis factor alpha.
}

birth," "corticosteroids, cortisol and bacterial vaginosis," "cortisol and vaginal infection," "cortisol and vaginal Lactobacilli," "cortisol and vaginal glycogen," "estrogen, vaginal glycogen and Lactobacillus dominance," a comprehensive search was conducted for scientific, peer-reviewed and published original research articles involving both humans and animal models, as well as review articles in PubMed/MEDLINE and Web of Science databases between December 2017 and August 2018. In order to comprehensively review relevant literature relating to psychosocial stress, cortisol levels, and maintenance of vaginal health, publication dates were not restricted. Articles not written in English or including other hormones not directly involved in the HPA or SAM stress axes and vaginal microbial composition (e.g., insulin), were not included.

\section{NORMAL VAGINAL MICROENVIRONMENT}

The human vagina is not only a passage for sperm, menstruum, and the baby but also a particularly versatile organ with a protective epithelium and a rich diverse microbial landscape (22). The vaginal microbiome comprises of a stratified squamous non-keratinized epithelium overlaid by a mucin-rich mucus layer and provides an attachment surface for the commensal and most dominant lactic acid producing Lactobacillus species. The most often identified species of Lactobacillus are L. crispatus, $L$. jensenii, L. gasseri, and $L$. iners $(23,24)$. Other bacteria endogenous to the normal vaginal microenvironment albeit with low virulence capacity include Gardnerella, Prevotella, Fusobacterium, Atopobium, Streptococcus, Staphylococcus, Peptostreptococcus, Porphyromonas etc. These potentially pathogenic bacteria are kept dormant by the acidic milieu ( $\mathrm{pH} 3.5-4.5)$ created by Lactobacilli amongst other protective mechanisms including production of lactic acid $(\sim 110 \mathrm{mM})$ $(25,26)$, hydrogen peroxide $\left(\mathrm{H}_{2} \mathrm{O}_{2}\right)$, antimicrobial peptides and by competitive exclusion i.e., physically preventing the attachment of pathogens to vaginal epithelium $(22,27,28)$. The commensal and potentially harmful vaginal microorganisms, their genes and products collectively form the vaginal microbiota that dwell in a regulated mutualistic relationship with the host vaginal epithelium to form the microbiome (29).

The vaginal microbiota in childhood until puberty is dominated by anaerobes due to low glycogen content, a decrease in Lactobacilli and other acid-producing microbes and a more alkaline $\mathrm{pH}$ (30). This increases their susceptibility to genital infections (e.g., vulvovaginitis) by a variety of aerobic and anaerobic pathogens including S. pyrogens, N. gonorrhea, E. coli, E. faecalis, C. vaginalis, Mycoplasmas, Diphtheroids, Bacteroides, S. epidermidis, C. albicans etc. (31-35). Fortunately, due to lack of exposure to sexual intercourse (coitus), the incidence of genital tract infections is low in children except in cases of child sexual abuse (36-38). At puberty, under the influence of rising estrogen levels, the vaginal epithelium thickens and stratifies, intracellular glycogen levels increase and undergo cyclical changes, cervicovaginal secretions are produced, and proliferation of lactic acid-producing lactobacilli commence (30, 39). The increasing production of lactic acid by Lactobacillus 
suggests there is a fermentable substrate present in the vagina. Glycogen is identified as the suitable carbohydrate substrate as an association between high acid secretion and presence of glycogen in the vagina was demonstrated over 80 years ago (40). Vaginal glycogen is degraded by host $\alpha$-amylase into maltose, maltotriose and $\alpha$-dextrins, which are then converted to lactic acid by Lactobacilli (21, 39, 41-43). Elevated estrogen and glycogen levels promote increased thickness of the stratified squamous epithelium and protective mucus layer of the vagina (44). Lactic acid at physiological concentration $(1 \% \mathrm{w} / \mathrm{v}, \sim 110 \mathrm{mM})(25,26$, 45 ) reduces the vaginal $\mathrm{pH}$, which encourages the proliferation of Lactobacilli and inhibits the growth of the anaerobes and viruses capable of causing infection $(26,39,45-49)$. It also exhibits some immunomodulatory effects on cervicovaginal epithelial cells and other cell types. It stimulates an anti-inflammatory state through the increased production of IL-1 receptor antagonist (IL-1RA) from cervicovaginal epithelial cells and inhibits the activation of nuclear factor- $\kappa \mathrm{B}(\mathrm{NF}-\kappa \mathrm{B})$ in peripheral blood mononuclear cells and monocytes-macrophages $(50,51)$, which promotes the transcription of pro-inflammatory target genes. In addition, it inhibits the Toll-like receptor (TLR)-induced production of inflammatory mediators from cervicovaginal epithelial cells. Both D- and L-lactic acid exhibit these antiinflammatory effects that are potentiated by low $\mathrm{pH}<3.86$ $(22,49,52)$. The homeostatic vaginal environment created by lactobacillus-dominant microbiota is temporarily altered during menstruation when there is a decline in estrogen and glycogen levels, and neutralization of the acidic $\mathrm{pH}$ promoting the growth of pathogenic bacteria such as Gardnerella, Prevotella, and Atopobium (53). After menstruation, the normal $\mathrm{pH}$ and Lactobacillus dominance are re-established as estrogen levels begin to rise again (54).

The vaginal microbiota in normal pregnancy is predominated by Lactobacilli species and is more stable than that in non-pregnant state $(55,56)$. This can be explained by the higher level of estrogen during pregnancy resulting in increased vaginal glycogen deposition, which enhances the proliferation of lactobacilli-dominated vaginal microbiota. As discussed later in this article, oestriol, which is one of three major endogenous estrogens produced in significantly larger amounts by the placenta during pregnancy (57), was as potent as $17 \beta$-oestradiol (the most common form of estrogen in non-pregnant premenopausal women) in stimulating vaginal glycogen deposition (58).

Following menopause, Lactobacilli dominance decreases secondary to diminished estrogen levels $(59,60)$ and cessation or decline of glycogen production (61). Loss of Lactobacilli increases vaginal $\mathrm{pH}$ to a more alkaline environment, providing a conducive habitat for colonization by anaerobes (possibly of fecal origin) and other pathogens $(30,62)$. For instance, postmenopausal women showed lower free genital fluid glycogen levels (41), and harbored more of G. vaginalis, Bacteroides, Peptostreptococcus, Streptococcus, and Prevotella (63) compared to premenopausal women who had higher free glycogen (41) and preponderance of L. crispatus and L. iners (64). Topical or systemic hormone replacement therapy and probiotics restore vaginal Lactobacillus dominance and homeostasis with increased acidity (65), and improves vaginal symptoms in post-menopausal women (44). In some cases, there is a decrease in the prevalence of anaerobic gram-negative rods and vaginal $\mathrm{pH}$ while the aerobic isolates including Lactobacilli remain fairly constant (65).

Though progesterone alone and in combination with estrogen greatly increases the glycogen concentration in the vaginal epithelium in squirrel monkeys (66), it does not appear to have the same effect in humans (58). For instance, progestin-only contraceptive drugs such as Depomedroxyprogesterone acetate (Depo-Provera) can produce a systemic hypoestrogenic state associated with slight thinning of the glycogen vaginal epithelial layer and reduced Lactobacillus colonization compromising the vaginal barrier against infection $(67,68)$. In fact, a significant negative correlation between free vaginal glycogen and progesterone level was recently reported in genital fluid samples of premenopausal women (42).

Also, the estrogenization and the subsequent production of glycogen by the vaginal epithelium have been shown to promote infection by Candida albicans (69). Glycogen was suggested to be a suitable substrate for C. albicans. This was particularly seen in post-menopausal women on systemic or vaginal estrogen therapy, whereas in a more recent study with premenopausal women, vulvovaginal candidiasis was observed in women with low vaginal $\alpha$-amylase activity (43). There is a need to investigate the relationship between $\alpha$-amylase activity and Lactobacillus dominance in post-menopausal women on and without estrogen therapy.

\section{PATHOGENESIS OF STRESS-INDUCED VAGINAL DYSBIOSIS}

The effect of stress on the incidence of BV may be mediated by stress-related dysregulation of immune function rather than behavioral changes associated with stress (20). An optimal immune response is required to prevent proliferation of BVassociated anaerobes. A sub-optimal response perhaps secondary to genetic polymorphism increases the risk of infection (70), and may allow more ascending genital tract infection (71). Stress enhances the progression of infection (including BV) and its pathophysiologic consequences $(72,73)$.

Perceived psychosocial stress is significantly and independently related to incidence and prevalence of $\mathrm{BV}$ in pregnant (74) and non-pregnant women (20). Some stress stimuli that can increase the risk of BV independent of individual behaviors include challenging life conditions such low income, poor housing, and dangerous neighborhood conditions, poor nutrition and interpersonal conflicts $(73,75)$. These studies assessed the level of stress exposure using the Cohen Perceived Stress Scale $(20,74,75)$. Chronic psychosocial stress is also an established risk factor for preterm delivery independent of other biomedical and behavioral risk factors (2). Stress regardless of pregnancy status can range from acute and severe (e.g., trauma), moderate (e.g., change in life events), and chronic (e.g., standing for long hours as part of daily occupation). Nevertheless, during pregnancy, both short- and long-term stress exposure can lead to adverse pregnancy and delivery outcome $(5,76-78)$, though 
some studies with in vitro fertilization (IVF) patients argue otherwise showing only minimal association between prenatal stress and adverse pregnancy outcome (79).

Stress-induced cortisol binds to glucocorticoid receptors expressed on a range of immune cells and alters NF- $\mathrm{B}$ activities, which regulates the activity of inflammatory mediators such as cytokines (IL-1 $\beta$, IL-6, TNF- $\alpha$, IFN $\gamma$ ) and chemokines (IL8, CCL5). Glucocorticoids also facilitates immunosuppression by inhibiting proliferation, migration and cytotoxicity of lymphocytes and leukocytes, and secretion of IL-2 and IFN$\gamma$ (73). On the other hand, stress-induced epinephrine and norepinephrine bind to adrenergic receptors, activate cAMP and stimulate the transcription of genes encoding for a variety of inflammatory mediators $(9,80)$. Higher stress scores correlate with higher levels of IL- 6 and TNF- $\alpha$; and with low levels of the anti-inflammatory cytokine IL-10 (5). Furthermore, stress hormones increase vulnerability to infections that are primarily prevented by innate and adaptive immune responses by differentially regulating monocyte, macrophage, Th1/Th2 cells and cytokine expression patterns (81-84). These cortisol and catecholamines-mediated changes in gene expression dysregulate immune function (9). However, with previous observation of stress-related alterations in production of inflammatory mediators that are not associated with serum cortisol levels (85), the impact of stress on immune function may not be limited to cortisol-mediated effects alone (20).

A stress-induced vaginal dysbiosis with disrupted vaginal mucosal and immune response-related proteins (e.g., lactoferrin), reduction in neutrophil bactericidal potency and reduced abundance of commensal Lactobacillus have been demonstrated in a mouse model (86). Reduced Lactobacillus was associated with overgrowth of other microbes (86), most likely anaerobic and facultative bacteria. Exposure to stress produces a significant decrease in the abundance of vaginal Lactobacillus species and can amplify the severity and consequences of vaginal infection (27). This occurs through the release of $\mathrm{CRH}$, which stimulates sympathetic nerve terminals and the SAM axis to release norepinephrine. Norepinephrine can enter the vagina from the bloodstream and is locally secreted by vaginal epithelial cells to which it binds (80). Though the vaginal epithelial cells in this in vitro experiment were exposed to a high range of norepinephrine concentrations $(1-10 \mu \mathrm{M})$, this may not differ significantly from the in vivo environment. This is supported by evidence of abundant supply of norepinephrine from nerve terminals innervating the cervicovaginal mucosa in humans and animals (87-91) and vaginal epithelial cells could potentially interact with norepinephrine in the circulation as well (80). In addition, local production of norepinephrine by epithelial cells in other sites such as the cornea has been demonstrated (92). The combined effect of a depleted vaginal Lactobacillus dominance, which leads to decreased lactic acid and $\mathrm{H}_{2} \mathrm{O}_{2}$ production and increased alkalinity and proliferation of pathogenic bacteria; and increased norepinephrine secretion result in a heightened pro-inflammatory response with increased production of cytokines and chemokines [(27); Figure 1]. In essence, high norepinephrine levels induced by severe stress, potentiates the pro-inflammatory response of vaginal epithelial cells possibly in an autocrine fashion in the presence of diminished Lactobacilli and low $\mathrm{pH}(80)$.

It also noteworthy that the incidence and prevalence of BV is influenced by other factors including frequent unprotected sexual activity with new or multiple partners (93-96), smoking, alcohol and drug use $(73,96-99)$, contraceptive practice $(97,98$, 100), vaginal douching $(95,97,101)$, menstruation $(102,103)$, pregnancy $(96,104)$, low educational and socioeconomic status, and black race $(73,95-98,100,105)$. Nevertheless, after adjusting for all of these associated factors that usually account for only minimal proportion of the variation in $\mathrm{BV}$, the relationship between psychosocial stress and aberrant vaginal microbiota has been shown to be maintained in several studies $(20,74)$. The pathophysiology, risk factors and consequences of BV and other female genital tract infections have been reviewed extensively $(22,106)$, and more investigation is recommended due to the enigmatic nature of these conditions especially BV.

\section{CORTISOL INHIBITS VAGINAL GLYCOGEN DEPOSITION}

The vaginal glycogen deposition action of estrogen was demonstrated over 50 years ago. Wrenn and colleagues in an attempt to determine the estrogen content of biological fluids, observed a rapid increase in vaginal glycogen content after locally administering estrogen extracted from human and cow urine and blood samples to adolescent, ovariectomized rats (58). This was termed the "vaginal glycogen assay for estrogen." Furthermore, they investigated the specificity of the assay by comparing the effect of $17 \beta$-oestradiol with progesterone, cortisol, deoxycorticosterone, testosterone and diethylstilboestrol (DES, synthetic non-steroidal estrogen), both individually and in combination with $17 \beta$-oestradiol. Of all these hormonal substances, which are equally applied intravaginally, only DES stimulated a vaginal glycogen response singly, which was significantly enhanced in combination with $17 \beta$-oestradiol. Interestingly, the hormones associated with stress i.e., cortisol (30 $\mu \mathrm{g} / 0.01 \mathrm{ml})$ and deoxycorticosterone $(40 \mu \mathrm{g} / 0.01 \mathrm{ml})$ exhibited moderate inhibition of the glycogen response when administered in combination with $17 \beta$-oestradiol, while progesterone and testosterone were ineffective in this regard. In addition, the vaginal glycogen action of the other two naturally occurring forms of estrogen was tested. It was observed that oestrone which is usually found in post-menopausal women was only about $10 \%$ as active as $17 \beta$-oestradiol, whereas oestriol (common during pregnancy) was as potent as $17 \beta$-oestradiol (58). This gives more credence to the more stable Lactobacilli dominated vaginal microbiota rich in glycogen and lactic acid content observed in healthy pregnant women. However, because this experiments were conducted in rats with relatively high concentrations of cortisol $\left(8.3 \times 10^{6} \mathrm{nmol} / \mathrm{l}\right)$ compared to circulating cortisol levels under maximum stress such as major surgery (726 and $1297 \mathrm{nmol} / \mathrm{l})(107,108)$ or intravenous administration of $50 \mathrm{mg}$ hydrocortisone (2450 nmol/l) (109) in humans, more empirical evidence from human experiments is required. Perhaps the local (cervicovaginal) concentrations of cortisol as demonstrated by 


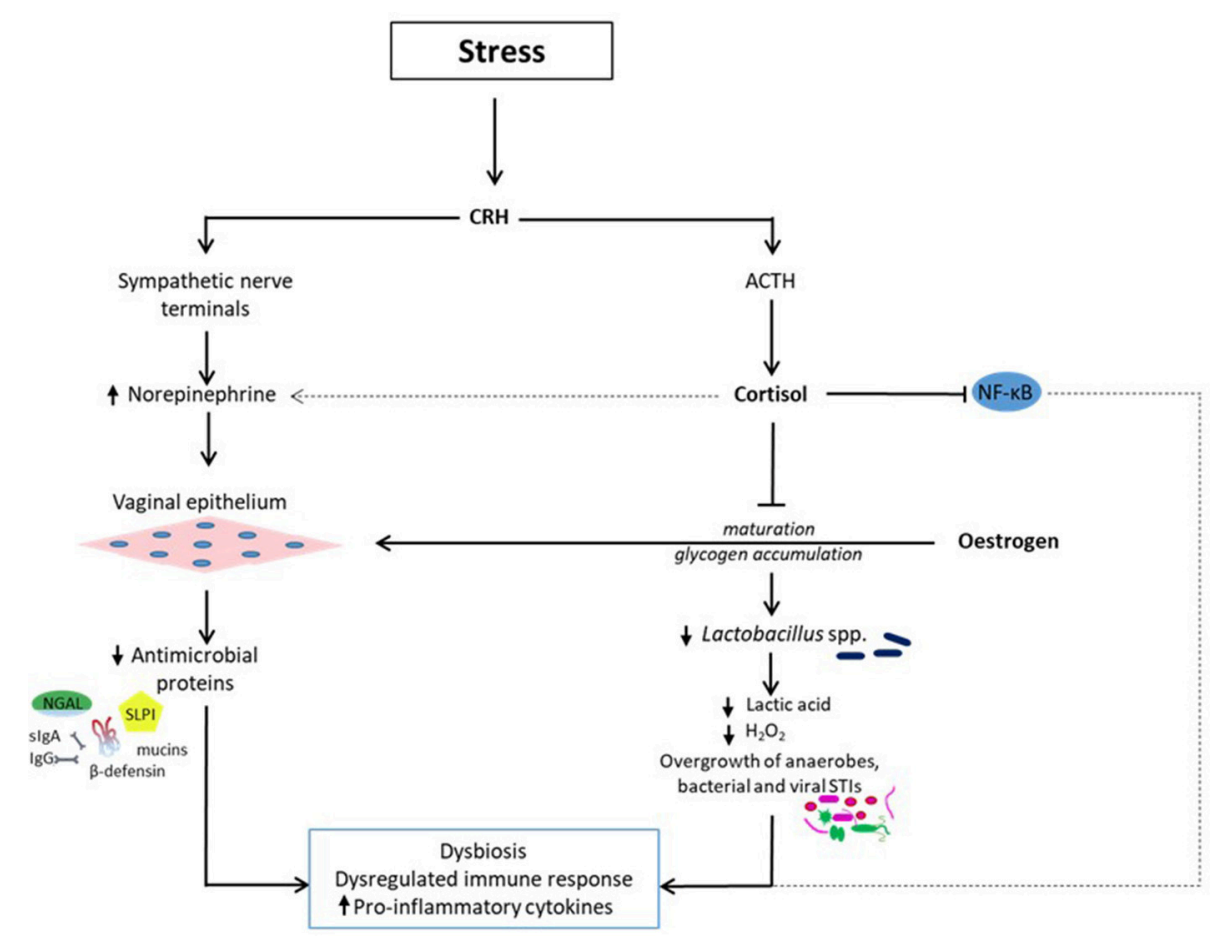

FIGURE 1 | Stress-related reduction in vaginal Lactobacillus dominance (dysbiosis) and dysregulated immune response. Exposure to psychosocial stress induces the release of cortisol and norepinephrine via the hypothalamic-pituitary-adrenal and SAM axes respectively. Cortisol inhibits the estrogen-related vaginal epithelial maturation and glycogen accumulation. Levels of vaginal free glycogen and Lactobacilli are reduced leading to decreased lactic acid and hydrogen peroxide $\left(\mathrm{H}_{2} \mathrm{O}_{2}\right)$ synthesis and $\mathrm{pH}$. Consequently, a dysbiotic environment conducive for the proliferation of bacterial vaginosis-associated anaerobic bacteria such as Gardnerella, Prevotella, Mobiluncus, Atopobium, Megasphera, and sexually transmitted infections such Neisseria gonorrhea, Chlamydia trachomatis, human immunodeficiency virus is created. Cortisol also affects immune response by altering the nuclear factor-kB (NF-kB) signal transduction pathway, which regulates inflammatory gene expression. These effects are exacerbated by the concurrent release of norepinephrine, which binds to vaginal epithelial cells and potentiates the pro-inflammatory response via a reduction in the release of antimicrobial proteins including mucins, immunoglobulins (secretory $\lg A$ and $\operatorname{lgG}$ ), $\beta$-defensins, secretory leucocyte protease inhibitor (SLPI), and neutrophil gelatinase-associated lipocalin (NGAL). The overall effect is a dysbiotic vaginal ecosystem with a sub-optimal immune response, which encourages upper genital tract infection with deleterious gynecological and obstetric sequelae.

Wrenn et al. (58) is more crucial in the glycogen response than the influence of circulating cortisol as reported in humans. More so, it could be that such repressive effect on vaginal glycogen deposition in humans could only be attained via a combined local action of cortisol and norepinephrine that mediate the physiologic stress response. This is yet to be demonstrated in human specimens.

The above evidence could be one mechanism through which frequent use of corticosteroids alters the equilibrium of the vaginal microbiome apart from dysregulated immune response. Cortisol repressed the estrogen-related maturation of vaginal epithelial cells and glycogen accumulation. If this happens in humans, the breakdown of glycogen to smaller polymers by $\alpha$-amylase is reduced leading to low lactic acid production and ultimately loss of Lactobacillus dominance. This recipe creates a conducive, less acidic ecosystem for infection by strict and facultative anaerobic bacteria, viruses, fungi, and protozoa (27). Because the maturation of the vaginal epithelium is impaired, there is inadequate secretion of mucins and other antimicrobial proteins such as secretory leukocyte protease inhibitor (SLPI), neutrophil gelatinase-associated lipocalin (NGAL), and $\beta$-defensins. In addition, cortisol also alters NF- $\kappa \mathrm{B}$ activity and dysregulates the expression of pro-inflammatory cytokines and chemokines (9). The combined effect is a dysregulated/ineffective inflammatory response against the pathogens, and an uncontrolled and possibly ascending genital tract infection, which can be deleterious especially during pregnancy.

Since stress is almost inevitable, these actions of cortisol have a propensity to disrupt the equilibrium of the vaginal microbiome and its capacity to combat infectious agents. Excessive exposure to psychosocial stress is independently associated with increased prevalence of $\mathrm{BV}(20,73-75)$, which is the most common vaginal condition in women of reproductive age. $\mathrm{BV}$ is a quintessential dysbiotic condition characterized by overgrowth of anaerobic gram-negative and gram-variable bacteria secondary to a decrease in the protective Lactobacillus species. During pregnancy, BV has been linked to stress and it increases the risk of preterm labor by $\sim 3$-fold (110). Infections such as $\mathrm{BV}$ can lead to ascending intrauterine infection that stimulates immune responses with release of inflammatory mediators, uterotonins (Prostaglandins, PGs) and extracellular matrix 
degrading enzymes (e.g., matrix metalloproteinases, MMPs). These inflammatory cytokines, chemokines, PGs, and MMPs stimulate the pathway to premature rupture of membranes and preterm birth i.e., uterine contraction, cervical ripening, and membrane activation, via a positive feedback loop $(22,28,106$, 110).

While studies on stress and vaginal dysbiosis are often done without measurement of cortisol levels (20, 74, 75, 111); and others did not find a clear pattern of association between perceived stress (resulting from change in relationships, sickness/injury, finances, work pressure or routines, unpleasant events, and relationship pressure) (111) or stress hormones and BV (112); the disruptive role of cortisol on the vaginal microbiota and immunity has been highlighted by the experiments of Wrenn et al. (58), albeit in animal models studied with significantly higher cortisol concentrations. Also, the correlation of cortisol levels with the prevalence of $\mathrm{BV}$ and other genitourinary tract infections in humans has been reported (113). In fact, a significant increase in cortisol across the 2 nd and $3 \mathrm{rd}$ trimesters was observed in patients with $\mathrm{BV}$, an association hypothesized to be restricted to a local response to cortisol (113). Elevated cortisol levels could correlate with reduced vaginal glycogen content, loss of Lactobacillus dominance, decreased acidity, dysbiosis, and increase production of proinflammatory mediators. More so, it is plausible that increased norepinephrine activity, which in concurrence with cortisol is involved in the "fight-or-flight" response and has been shown to potentiate the pro-inflammatory response of vaginal epithelial cells, amplifies these actions of cortisol (Figure 1). Furthermore, since vaginal glycogen deposition is not required for immediate survival during exposure to stressful stimuli and subsequent "fight-or-flight" response, cortisol's action appears to be an adaptive mechanism to preserve energy sources for organs such as the brain, cardiac and skeletal muscles albeit with unpleasant reproductive consequences when prolonged. A more comprehensive investigation to elucidate the mechanisms of cortisol's action on the human vaginal microflora and the consequent gynecological and obstetric health implications is required.

\section{STRESS-INDUCED ALTERED MATERNAL VAGINAL AND OFFSPRING GUT MICROBIOTA}

Exposure to chronic psychosocial stress during pregnancy may amplify the physiologic pregnancy-induced immunosuppression (114). This can increase the risk of dysbiosis, recurrent genitourinary infection and eventual loss of the beneficial lactobacillus-dominated vaginal microbiota as seen in BV and candidiasis $(115,116)$. Since the initial neonatal gut microbial colonization is dependent on vertical transmission from the maternal vaginal microbiota during parturition, acquisition of a dysbiotic lactobacillus-depleted microbiota predisposes the infant to altered gastrointestinal tract maturation, impaired extraction of energy and macromolecules essential for normal growth and development, and dysfunctional immune system.
This eventually increases the infant's risk of disturbed energy metabolism, obesity, insulin resistance, and diabetes mellitus. Other conditions include diarrheal illness, food allergy, atopic diseases, and inflammatory bowel disease, and irritable bowel syndrome $(117,118)$. Also, the risk of long-term neurodevelopmental disorders due to reprogramming of the developing brain has been reported $(86,114,119)$. These findings are supported by human studies and experiments with animal models. For instance, infants of mothers with high prenatal stress (reported and due to high cortisol levels) had significantly lower relative abundance of lactic acid-producing bacteria including Lactobacillus, Lactoccus, Aerococcus, and Bifidobacteria; and higher relative abundance of Proteobacteria including the pathogenic E. coli, Serratia, and Enterobacter. This dysbiotic microbiota is potentially associated with an increased level of lipopolysaccharide (LPS)-induced inflammation and more maternally-reported infant gastrointestinal symptoms and allergic reactions (118).

Furthermore, female rhesus monkeys exposed to moderate stress (acoustic startle) for 6 weeks in later gestation showed activated HPA axis and increased cortisol levels (above those found in normal pregnancy), that was sufficient to cause altered intestinal microbiota characterized by decreased protective Lactobacilli and Bifidobacteria in their offsprings (120). Reduced concentrations of Lactobacilli and total and Gram-negative aerobes and facultative anaerobes have also been observed in the small intestine of pups whose mothers were injected with cortisone before birth $(121,122)$. These animal studies have provided ample evidence that the relationship between prenatal psychosocial stress and offspring programming is mediated, at least in part, by elevated cortisol levels (119). The pathophysiology of the effect of prenatal stress on maternal gut/vaginal and fetal gut microbial composition, and the development of insulin resistance, increased adiposity and metabolic syndrome later in life in humans is beyond the scope of this review but requires further investigation.

\section{PREVENTIVE AND TREATMENT STRATEGIES FOR STRESS-INDUCED VAGINAL INFECTION AND INFLAMMATION}

Optimal preventive/treatment approach to counteract the effect of stress on vthe aginal microenvironment should aim to alleviate or eliminate the stress stimuli and the associated infectious and inflammation agent(s). Though stress is almost inevitable, some life modifications can help an individual cope with stressors better. These adaptive measures include regular physical exercise, healthy eating, having adequate sleep and avoiding unhealthy habits like smoking, alcohol, and drug abuse. In addition to eliminating stressors and lifestyle modifications, appropriately administered antibiotics or antifungal agents can eliminate bacterial and fungal infections while inflammation can be targeted pharmacologically using anti-inflammatory agents. This is an important therapeutic goal because inflammation can persist even after the stress 
stimuli or infectious agents have been eliminated (22). Antibiotic treatment may also alter the vaginal bacterial composition with potential colonization by opportunistic pathogenic agents (123).

Another potential approach to restoring and/or maintaining vaginal homeostasis that avoids the adverse effect of antibiotics on beneficial microbiota (124) is the use of probiotics e.g., Lactobacillus species (L. crispatus), and prebiotics such as D-lactic acid, glycogen, oligosaccharide etc. that stimulate probiotic bacterial growth $(22,124-131)$. Recently, in a study including 6 women, 5 of whom were pregnant, vaginal, and oral lactoferrin administration improved vaginal microbiota Lactobacillus dominance and prevented refractory BV, cervical inflammation, and preterm delivery (132). This has previously been attempted with similar results by the same group (133) and others (134); and gives credence to the observed altered vaginal microbiota (with decreased Lactobacilli and lactoferrin levels) when mice were exposed to mild prenatal stress (86). A combination of probiotics and prebiotics could provide clinically useful adjunct to pharmacological and other strategies for treating/preventing vaginal infections and women's health in general $(129,131)$.

Some anti-inflammatory agents that can block LPS-driven production of cytokines (e.g., TNF- $\alpha$, IL-6 and IL-1 $\beta$ ) as observed in stress-induced vaginal colonization by anaerobic bacteria include phosphodiesterase (PDE) inhibitors, MAP kinase inhibitors, TNF biologics and NF- $\kappa \mathrm{B}$ inhibitors (135). Some of these agents have also been applied in the prevention of LPS-stimulated preterm birth and fetal death $(136,137)$. With further exploration of the clinical utility, safety and toxicity of these anti-inflammatory agents, various stages of the stress/infection-associated inflammatory process can be targeted. However, because NF- $\mathrm{B}$ is the "master regulator" of inflammatory gene expression, there is the crucial concern that inhibiting the activation of NF- $\kappa \mathrm{B}$ and/or other proinflammatory mediators could prevent optimal activation of host innate and adaptive immune responses and increase the risk of infection. This could be deleterious particularly in an immunocompromised state such as pregnancy $(135,138)$.

\section{REFERENCES}

1. Wadhwa PD, Culhane JF, Rauh V, Barve SS. Stress and preterm birth: neuroendocrine, immune/inflammatory, and vascular mechanisms. Matern Child Health J. (2001) 5:119-25. doi: 10.1023/A:1011353216619

2. Wadhwa PD, Culhane JF, Rauh V, Barve SS, Hogan V, Sandman $\mathrm{CA}$, et al. Stress, infection and preterm birth: a biobehavioural perspective. Paediatr Perinat Epidemiol. (2001) 15(Suppl. 2):17-29. doi: 10.1046/j.1365-3016.2001.00005.x

3. Chrousos GP. Regulation and dysregulation of the hypothalamicpituitary-adrenal axis. The corticotropin-releasing hormone perspective. Endocrinol Metab Clin North Am. (1992) 21:833-58. doi: 10.1016/S0889-8529(18)30191-9

4. Orr ST, James SA, Casper R. Psychosocial stressors and low birth weight: development of a questionnaire. J Dev Behav Pediatr. (1992) 13:343-7. doi: 10.1097/00004703-199210010-00005

5. Coussons-Read ME, Okun ML, Schmitt MP, Giese S. Prenatal stress alters cytokine levels in a manner that may endanger human pregnancy.

\section{MAIN FINDINGS AND FUTURE DIRECTION}

The potential action of the stress hormone cortisol in the maintenance of vaginal health has been highlighted. Stress stimuli are ubiquitous and women do not enjoy any exemptions. The physiologic "fight-or-flight" response may be deleterious to their lower genital tract microbiome if the stress stimuli persist for longer than necessary. Persistent exposure to psychosocial stress and stimulation of the HPA and SAM axes, with a corresponding increase in cortisol and norepinephrine levels are associated with dysbiosis and increased susceptibility to several infections including genitourinary tract infections. Though this could be solely due to a dysregulated immune response, a cortisol-induced inhibition of vaginal glycogen deposition may be involved especially in the instance of vaginal infection. The estrogen-related increased vaginal glycogen deposition and epithelial maturation are requirements for the maintenance of vaginal eubiosis. The ability of cortisol to disrupt this process as shown in animal models is important in the pathogenesis of vaginal dysbiosis and subsequent development of infection and inflammation. If proven in humans, this phenomenon may be more crucial in pregnancy where a healthy Lactobacillusdominated vaginal microbiome is sacrosanct, and there is local production of more $\mathrm{CRH}$ from gestational tissues including the decidua, fetal membranes (chorioamnion), and placenta. Because the current evidence of the repressive role of cortisol on vaginal glycogen deposition involve experiments in animals with high concentrations of cortisol compared to that observed during severe stress in humans, further work especially in humans is needed to elucidate the pathophysiologic association between cortisol levels and vaginal microbiomial architecture and function.

\section{AUTHOR CONTRIBUTIONS}

EA conceived the research idea and conducted the literature search. EA and DA contributed to writing the manuscript. Both authors revised and approved the submission of the final manuscript.
Psychosom Med. (2005) 67:625-31. doi: 10.1097/01.psy.0000170331. 74960.ad

6. Sapolsky RM, Romero LM, Munck AU. How do glucocorticoids influence stress responses? Integrating permissive, suppressive, stimulatory, and preparative actions. Endocr Rev. (2000) 21:55-89. doi: 10.1210/er.21.1.55

7. Munck A, Náray-Fejes-Tóth A. The ups and downs of glucocorticoid physiology Permissive and suppressive effects revisited. Mol Cell Endocrinol. (1992) 90:C1-4. doi: 10.1016/0303-7207(92)90091-J

8. Chrousos GP, Kino T. Glucocorticoid action networks and complex psychiatric and/or somatic disorders. Stress (2007) 10:213-9. doi: 10.1080/10253890701292119

9. Padgett DA, Glaser R. How stress influences the immune response. Trends in Immunology (2003) 24:444-8. doi: 10.1016/S1471-4906(03) 00173-X

10. Bergland C. Cortisol: Why "The Stress Hormone" Is Public Enemy No 1 (2013). Available online at: https://www.psychologytoday.com/blog/theathletes-way/201301/cortisol-why- the-stress-hormone-is-public-enemyno-1 (Accessed April 4, 2018). 
11. Shrayyef MZ, Gerich JE. Normal glucose homeostasis. In: Poretsky L, editor. Principles of Diabetes Mellitus. 2nd ed. Boston, MA: Springer (2010) p. 19-35.

12. Kamba A, Daimon M, Murakami H, Otaka H, Matsuki K, Sato E, et al. Association between higher serum cortisol levels and decreased insulin secretion in a general population. PLOS ONE (2016) 11:e0166077. doi: 10.1371/journal.pone.0166077

13. Chung S, Son GH, Kim K. Circadian rhythm of adrenal glucocorticoid: Its regulation and clinical implications. Biochim Biophys Acta (2011) 1812:58191. doi: 10.1016/j.bbadis.2011.02.003

14. Knight RP Jr, Kornfeld DS, Glaser GH, Bondy PK. Effects of intravenous hydrocortisone on electrolytes of serum and urine in man. J Clin Endocrinol Metab. (1955) 15:176-81. doi: 10.1210/jcem-15-2-176

15. Sandle GI, Keir MJ, Record CO. The effect of hydrocortisone on the transport of water, sodium, and glucose in the jejunum. Scand J Gastroenterol. (1981) 16:667-71. doi: 10.3109/00365528109182028

16. Ackermann S, Hartmann F, Papassotiropoulos A, Quervain DJ-Fd, Rasch B. Associations between basal cortisol levels and memory retrieval in healthy young individuals. J Cogn Neurosci. (2013) 25:1896-907. doi: 10.1162/jocn_a_00440

17. Chyun YS, Kream BE, Raisz LG. Cortisol decreases bone formation by inhibiting periosteal cell proliferation. Endocrinology (1984) 114:477-80. doi: 10.1210/endo-114-2-477

18. Stratakis CA, Chrousos GP. Neuroendocrinology and pathophysiology of the stress system. Ann N Y Acad Sci. (1995) 771:1-18.

19. Debono M, Ghobadi C, Rostami-Hodjegan A, Huatan H, Campbell MJ, Newell-Price J, et al. Modified-Release Hydrocortisone to provide circadian cortisol profiles. J Clin Endocrinol Metab. (2009) 94:1548-54. doi: 10.1210/jc.2008-2380

20. Nansel TR, Riggs MA, Klebanoff M. The association of psychosocial stress and bacterial vaginosis in a longitudinal cohort. Am J Obstet Gynecol. (2006) 194:381-6. doi: 10.1016/j.ajog.2005.07.047

21. Mirmonsef P, Hotton AL, Gilbert D, Burgad D, Landay A, Weber KM, et al. Free glycogen in vaginal fluids is associated with Lactobacillus colonization and low vaginal pH. PLoS ONE (2014) 9:e102467. doi: 10.1371/journal.pone.0102467

22. Amabebe E, Anumba DOC. The vaginal microenvironment: the physiologic role of Lactobacilli. Front Med. (2018) 5:181. doi: 10.3389/fmed.2018.00181

23. Petrova MI, Lievens E, Malik S, Imholz N, Lebeer S. Lactobacillus species as biomarkers and agents that can promote various aspects of vaginal health. Front Physiol. (2015) 6:81. doi: 10.3389/fphys.2015.00081

24. Ravel J, Gajer P, Abdo Z, Schneider GM, Koenig SS, McCulle SL, et al. Vaginal microbiome of reproductive-age women. Proc Natl Acad Sci USA. (2011) 108(Suppl. 1):4680-7. doi: 10.1073/pnas.1002 611107

25. Aldunate M, Srbinovski D, Hearps AC, Latham CF, Ramsland PA, Gugasyan R, et al. Antimicrobial and immune modulatory effects of lactic acid and short chain fatty acids produced by vaginal microbiota associated with eubiosis and bacterial vaginosis. Front Physiol. (2015) 6:164. doi: 10.3389/fphys.2015.00164

26. O'Hanlon DE, Moench TR, Cone RA. Vaginal $\mathrm{pH}$ and microbicidal lactic acid when lactobacilli dominate the microbiota. PLoS ONE (2013) 8:e80074. doi: 10.1371/journal.pone.0080074

27. Witkin SS, Linhares IM. Why do lactobacilli dominate the human vaginal microbiota? BJOG (2017) 124:606-11. doi: 10.1111/1471-0528.14390

28. Witkin S. The vaginal microbiome, vaginal anti-microbial defence mechanisms and the clinical challenge of reducing infection-related preterm birth. BJOG (2015) 122:213-8. doi: 10.1111/1471-0528.13115

29. Marchesi JR, Ravel J. The vocabulary of microbiome research: a proposal. Microbiome (2015) 3:31. doi: 10.1186/s40168-015-0094-5

30. Farage M, Maibach H. Lifetime changes in the vulva and vagina. Arch Gynecol Obstet. (2006) 273:195-202. doi: 10.1007/s00404-005-0079-x

31. Dasari S, Anandan SK, Rajendra W, Valluru L. Role of microbial flora in female genital tract: a comprehensive review. Asian Pacific J Trop Dis. (2016) 6:909-17. doi: 10.1016/S2222-1808(16)61155-6

32. Hammerschlag MR, Alpert S, Onderdonk AB, Thurston P, Drude E, McCormack WM, et al. Anaerobic microflora of the vagina in children. Am J Obstet Gynecol. (1978) 131:853-6. doi: 10.1016/S0002-9378(16)33130-1
33. Hammerschlag MR, Alpert S, Rosner I, Thurston P, Semine D, McComb $\mathrm{D}$, et al. Microbiology of the vagina in children: normal and potentially pathogenic organisms. Pediatrics (1978) 62:57-62.

34. Gerstner GJ, Grunberger W, Boschitsch E, Rotter M. Vaginal organisms in prepubertal children with and without vulvovaginitis. A vaginoscopic study. Arch Gynecol. (1982) 231:247-52. doi: 10.1007/BF02110125

35. Bumbuliene Ž, Venclavičiute K, Ramašauskaite $D$, Arlauskiene A, Bumbul E, Drasutiene G. Microbiological findings of vulvovaginitis in prepubertal girls. Postgraduate Med J. (2014) 90:8-12. doi: 10.1136/postgradmedj-2013-131959

36. Jaquiery A, Stylianopoulos A, Hogg G, Grover S. Vulvovaginitis: clinical features, aetiology, and microbiology of the genital tract. Arch Dis Child (1999) 81:64-7.

37. Jones R. Childhood vulvovaginitis and vaginal discharge in general practice. Fam Pract. (1996) 13:369-72. doi: 10.1093/fampra/13.4.369

38. Hayes L, Creighton SM. Prepubertal vaginal discharge. Obstet Gynaecol. (2007) 9:159-63. doi: 10.1576/toag.9.3.159.27335

39. Spear GT, French AL, Gilbert D, Zariffard MR, Mirmonsef P, Sullivan TH, et al. Human $\alpha$-amylase present in lower genital tract mucosal fluid processes glycogen to support vaginal colonization by Lactobacillus. J Infect Dis. (2014): 210:1019-28. doi: 10.1093/infdis/jiu231

40. Robert C. The conversion of the glycogen of the vagina into lactic acid. $J$ Pathol Bacteriol. (1934) 39:213-9. doi: 10.1002/path.1700390118

41. Mirmonsef P, Modur S, Burgad D, Gilbert D, Golub ET, French AL, et al. An exploratory comparison of vaginal glycogen and Lactobacillus levels in pre- and post-menopausal women. Menopause (2015) 22:702-9. doi: 10.1097/GME.0000000000000397

42. Mirmonsef P, Hotton AL, Gilbert D, Gioia CJ, Maric D, Hope TJ, et al. Glycogen levels in undiluted genital fluid and their relationship to vaginal $\mathrm{pH}$, estrogen, and progesterone. PLoS ONE (2016) 11:e0153553. doi: 10.1371 /journal.pone. 0153553

43. Nasioudis D, Beghini J, Bongiovanni AM, Giraldo PC, Linhares IM, Witkin SS. $\alpha$-amylase in vaginal fluid:association with conditions favorable to dominance of Lactobacillus. Reprod Sci. (2015) 22:1393-8. doi: $10.1177 / 1933719115581000$

44. Muhleisen AL, Herbst-Kralovetz MM. Menopause and the vaginal microbiome. Maturitas (2016) 91:42-50. doi: 10.1016/j.maturitas.2016.05.015

45. Aldunate M, Tyssen D, Johnson A, Zakir T, Sonza S, Moench T, et al. Vaginal concentrations of lactic acid potently inactivate HIV.J Antimicrob Chemoth. (2013) 68:2015-25. doi: 10.1093/jac/dkt156

46. Smith SB, Ravel J. The vaginal microbiota, host defence and reproductive physiology. J Physiol. (2017) 595:451-63. doi: 10.1113/JP271694

47. Tyssen D, Wang YY, Hayward JA, Agius PA, DeLong K, Aldunate M, et al. Anti-HIV-1 activity of lactic acid in human cervicovaginal fluid. $m$ Sphere (2018) 3:e00055-18. doi: 10.1128/mSphere.00055-18

48. Aldunate M, Tyssen D, Latham C, Ramsland P, Perlmutter P, Moench T, et al. Vaginal concentrations of lactic acid potently inactivate HIV-1 compared to short chain fatty acids present during bacterial vaginosis. AIDS Res Hum Retrovirus. (2014) 30:2015-25. doi: 10.1089/aid.2014.5499.abstract

49. Hearps AC, Tyssen D, Srbinovski D, Bayigga L, Diaz DJD, Aldunate M, et al. Vaginal lactic acid elicits an anti-inflammatory response from human cervicovaginal epithelial cells and inhibits production of pro-inflammatory mediators associated with HIV acquisition. Mucosal Immunol. (2017) 10:1480. doi: 10.1038/mi.2017.27

50. Lee JM, Hwang KT, Jun WJ, Park CS, Lee MY. Antiinflammatory effect of lactic acid bacteria: inhibition of cyclooxygenase-2 by suppressing nuclear factor-kappaB in Raw264.7 macrophage cells. J Microbiol Biotechnol. (2008) 18:1683-8.

51. Ménard S, Candalh C, Bambou JC, Terpend K, Cerf-Bensussan N, Heyman M. Lactic acid bacteria secrete metabolites retaining antiinflammatory properties after intestinal transport. Gut (2004) 53:821-8. doi: 10.1136/gut.2003.026252

52. Tachedjian G, Aldunate M, Bradshaw CS, Cone RA. The role of lactic acid production by probiotic Lactobacillus species in vaginal health. Res Microbiol. (2017) 168:782-92. doi: 10.1016/j.resmic.2017.04.001

53. Lopes dos Santos Santiago G, Tency I, Verstraelen H, Verhelst R, Trog M, Temmerman M, et al. Longitudinal qPCR study of the dynamics of $L$. 
crispatus, L. iners, A. vaginae, (Sialidase Positive) G. vaginalis, and P. bivia in the Vagina. PLoS ONE (2012) 7:e45281. doi: 10.1371/journal.pone.0045281

54. Srinivasan S, Liu C, Mitchell CM, Fiedler TL, Thomas KK, Agnew $\mathrm{KJ}$, et al. Temporal variability of human vaginal bacteria and relationship with bacterial vaginosis. PloS ONE (2010) 5:e10197. doi: 10.1371/journal.pone.0010197

55. Romero R, Hassan SS, Gajer P, Tarca AL, Fadrosh DW, Nikita L, et al. The composition and stability of the vaginal microbiota of normal pregnant women is different from that of non-pregnant women. Microbiome (2014) 2:4. doi: 10.1186/2049-2618-2-4

56. DiGiulio DB, Callahan BJ, McMurdie PJ, Costello EK, Lyell DJ, Robaczewska A, et al. Temporal and spatial variation of the human microbiota during pregnancy. Proc Natl Acad Sci USA. (2015) 112:11060-5. doi: $10.1073 /$ pnas.1502875112

57. Mesiano S. CHAPTER 11 - The endocrinology of human pregnancy and fetoplacental neuroendocrine development. In: Strauss JF, Barbieri RL, editors. Yen \& Jaffe's Reproductive Endocrinology. 6th ed. Philadelphia, PA: W.B. Saunders (2009) p. 249-81.

58. Wrenn TR, Wood JR, Bitman J, Brinsfield TH. Vaginal glycogen assay for oestrogen: specificity and application to blood and urine. J Reprod Fertil. (1968) 16:301-4. doi: 10.1530/jrf.0.0160301

59. Cauci S, Driussi S, De Santo D, Penacchioni P, Iannicelli T, Lanzafame $\mathrm{P}$, et al. Prevalence of bacterial vaginosis and vaginal flora changes in peri- and postmenopausal women. J Clin Microbiol. (2002) 40:2147-52. doi: 10.1128/JCM.40.6.2147-2152.2002

60. Gupta S, Kumar N, Singhal N, Kaur R, Manektala U. Vaginal microflora in postmenopausal women on hormone replacement therapy. Indian J Pathol Microbiol. (2006) 49:457-61.

61. Cruickshank R, Sharman A. The biology of the vagina in the human subject. BJOG (1934) 41:208-26. doi: 10.1111/j.1471-0528.1934.tb08759.x

62. Calleja-Agius J, Brincat MP. Urogenital atrophy. Climacteric (2009) 12:27985. doi: 10.1080/13697130902814751

63. Burton JP, Reid G. Evaluation of the bacterial vaginal flora of 20 postmenopausal women by direct (Nugent score) and molecular (polymerase chain reaction and denaturing gradient gel electrophoresis) techniques. J Infect Dis. (2002) 186:1770-80. doi: 10.1086/345761

64. Brotman RM, Shardell MD, Gajer P, Fadrosh D, Chang K, Silver MI. Association between the vaginal microbiota, menopause status, and signs of vulvovaginal atrophy. Menopause (2014) 21:450-8. doi: 10.1097/GME.0b013e3182a4690b

65. Ginkel PD, Soper DE, Bump RC, Dalton HP. Vaginal flora in postmenopausal women: the effect of estrogen replacement. Infect Dis Obstet Gynecol. (1993) 1:94-7. doi: 10.1155/S1064744993000225

66. Bo WJ. The effect of progesterone and progesterone-estrogen on the glycogen deposition in the vagina of the squirrel monkey. Am J Obstet Gynecol. (1970) 107:524-30. doi: 10.1016/S0002-9378(16)33936-9

67. Miller L, Patton DL, Meier A, Thwin SS, Hooton TM, Eschenbach DA. Depomedroxyprogesterone-induced hypoestrogenism and changes in vaginal flora and epithelium. Obstet Gynecol. (2000) 96:431-9. doi: 10.1016/S0029-7844(00)00906-6

68. Eschenbach DA, Patton DL, Meier A, Thwin SS, Aura J, Stapleton A, et al. Effects of oral contraceptive pill use on vaginal flora and vaginal epithelium. Contraception (2000) 62:107-12. doi: 10.1016/S0010-7824(00)00155-4

69. Dennerstein GJ, Ellis DH. Oestrogen, glycogen and vaginal candidiasis. Aust $N \quad Z \quad J$ Obstet Gynaecol. (2001) 41:326-8. doi: 10.1111/j.1479-828X.2001.tb01238.x

70. Goepfert AR, Varner M, Ward K, Macpherson C, Klebanoff M, Goldenberg RL, et al. Differences in inflammatory cytokine and Toll-like receptor genes and bacterial vaginosis in pregnancy. Am J Obstet Gynecol. (2005) 193:147885. doi: 10.1016/j.ajog.2005.03.053

71. Manns-James L. Bacterial vaginosis and preterm birth. J Midwifery Womens Health (2011) 56:575-83. doi: 10.1111/j.1542-2011.2011.00086.x

72. Biondi M, Zannino LG. Psychological stress, neuroimmunomodulation, and susceptibility to infectious diseases in animals and man: a review. Psychother Psychosom. (1997) 66:3-26. doi: 10.1159/000289101

73. Culhane JF, Rauh VA, Goldenberg RL. Stress, bacterial vaginosis, and the role of immune processes. Curr Infect Dis Rep. (2006) 8:459-64. doi: $10.1007 / \mathrm{s} 11908-006-0020-\mathrm{x}$
74. Culhane JF, Rauh V, McCollum KF, Hogan VK, Agnew K, Wadhwa $\mathrm{PD}$. Maternal stress is associated with bacterial vaginosis in human pregnancy. Matern Child Health J. (2001) 5:127-34. doi: 10.1023/A:10113053 00690

75. Culhane JF, Rauh V, McCollum KF, Elo IT, Hogan V. Exposure to chronic stress and ethnic differences in rates of bacterial vaginosis among pregnant women. Am J Obstet Gynecol. (2002) 187:1272-6. doi: $10.1067 / \mathrm{mob} .2002 .127311$

76. Dole N, Savitz DA, Hertz-Picciotto I, Siega-Riz AM, McMahon MJ, Buekens P. Maternal stress and preterm birth. Am J Epidemiol. (2003) 157:14-24. doi: $10.1093 /$ aje/kwfl76

77. Austin MP, Leader L. Maternal stress and obstetric and infant outcomes: epidemiological findings and neuroendocrine mechanisms. Aust NZ J Obstet Gynaecol. (2000) 40:331-7. doi: 10.1111/j.1479-828X.2000.tb03344.x

78. Gennaro S, Fehder WP. Stress, immune function, and relationship to pregnancy outcome. Nurs Clin North Am. (1996) 31:293-303.

79. Milad MP, Klock SC, Moses S, Chatterton R. Stress and anxiety do not result in pregnancy wastage. Hum Reprod. (1998) 13:2296-300. doi: 10.1093/humrep/13.8.2296

80. Brosnahan AJ, Vulchanova L, Witta SR, Dai Y, Jones BJ, Brown DR. Norepinephrine potentiates proinflammatory responses of human vaginal epithelial cells. J Neuroimmunol. (2013) 259:8-16. doi: 10.1016/j.jneuroim.2013.03.005

81. Elenkov IJ, Chrousos GP. Stress hormones, Th1/Th2 patterns, pro/antiinflammatory cytokines and susceptibility to disease. Trends Endocrinol Metab. (1999) 10:359-68.

82. Elenkov IJ, Chrousos GP. Stress, cytokine patterns and susceptibility to disease. Baillieres Best Pract Res Clin Endocrinol Metab. (1999) 13:583-95. doi: 10.1053/beem.1999.0045

83. Elenkov IJ, Webster EL, Torpy DJ, Chrousos GP. Stress, corticotropinreleasing hormone, glucocorticoids, and the immune/inflammatory response: acute and chronic effects. Ann N Y Acad Sci. (1999) 876:1-11; discussion:3..

84. Chrousos GP. Stressors, stress, and neuroendocrine integration of the adaptive response. The 1997 Hans Selye Memorial Lecture. Ann N Y Acad Sci. (1998) 851:311-35.

85. Song C, Kenis G, van Gastel A, Bosmans E, Lin A, de Jong R, et al. Influence of psychological stress on immune-inflammatory variables in normal humans. Part II. Altered serum concentrations of natural anti-inflammatory agents and soluble membrane antigens of monocytes and T lymphocytes. Psychiatry Res. (1999) 85:293-303. doi: 10.1016/S0165-1781(99) 00012-8

86. Jašarević $\mathrm{E}$, Howerton $\mathrm{CL}$, Howard $\mathrm{CD}$, Bale TL. Alterations in the vaginal microbiome by maternal stress are associated with metabolic reprogramming of the offspring gut and brain. Endocrinology (2015) 156:3265-76. doi: 10.1210/en.2015-1177

87. Pauls R, Mutema G, Segal J, Silva WA, Kleeman S, Dryfhout V, et al. Original research-basic science: a prospective study examining the anatomic distribution of nerve density in the human vagina. J Sex Med. (2006) 3:979-87. doi: 10.1111/j.1743-6109.2006.00325.x

88. Hilliges M, Falconer C, Ekman-Ordeberg G, Johansson O. Innervation of the human vaginal mucosa as revealed by PGP 9.5 immunohistochemistry. Cells Tissues Organs (1995) 153:119-26. doi: 10.1159/000147722

89. Mónica Brauer M, Smith PG. Estrogen and female reproductive tract innervation: cellular and molecular mechanisms of autonomic neuroplasticity. Auton Neurosci. (2015) 187:1-17. doi: 10.1016/j.autneu.2014.11.009

90. Owman C, Rosengren E, Sjöberg NO. Adrenergic innervation of the human female reproductive organs: a histochemical and chemical investigation. Obstet Gynecol. (1967) 30:763-73.

91. łakomy M, Kaleczyc J, Majewski M, Sienkiewicz W. Peptidergic innervation of the bovine vagina and uterus. Acta Histochemica (1995) 97:53-66. doi: 10.1016/S0065-1281(11)80206-0

92. Pullar CE, Zhao M, Song B, Pu J, Reid B, Ghoghawala S, et al. Badrenergic receptor agonists delay while antagonists accelerate epithelial wound healing: evidence of an endogenous adrenergic network within the corneal epithelium. J Cell Physiol. (2007) 211:261-72. doi: 10.1002/jcp. 20934 
93. Verstraelen $H$, Verhelst $R$, Vaneechoutte $M$, Temmerman $M$. The epidemiology of bacterial vaginosis in relation to sexual behaviour. BMC Infect Dis. (2010) 10:81. doi: 10.1186/1471-2334-10-81

94. Nilsson U, Hellberg D, Shoubnikova M, Nilsson S, Mårdh PA. Sexual behavior risk factors associated with bacterial vaginosis and Chlamydia trachomatis Infection. Sex Transm Dis. (1997) 24:241-6. doi: 10.1097/00007435-199705000-00001

95. Allsworth JE, Peipert JF. Prevalence of bacterial vaginosis: 2001-2004 national health and nutrition examination survey data. Obstet Gynecol. (2007) 109:114-20. doi: 10.1097/01.AOG.0000247627.84791.91

96. Koumans EH, Sternberg M, Bruce C, McQuillan G, Kendrick J, Sutton M, et al. The prevalence of bacterial vaginosis in the United States, 2001-2004; associations with symptoms, sexual behaviors, and reproductive health. Sex Transm Dis. (2007) 34:864-9. doi: 10.1097/OLQ.0b013e318074e565

97. Cherpes TL, Hillier SL, Meyn LA, Busch JL, Krohn MA. A delicate balance: risk factors for acquisition of bacterial vaginosis include sexual activity, absence of hydrogen peroxide-producing lactobacilli, black race, and positive herpes simplex virus type 2 serology. Sex Transm Dis. (2008) 35:78-83. doi: 10.1097/OLQ.0b013e318156a5d0

98. Ness RB, Hillier S, Richter HE, Soper DE, Stamm C, Bass DC, et al. Can known risk factors explain racial differences in the occurrence of bacterial vaginosis? J Natl Med Assoc. (2003) 95:201-12.

99. Hellberg D, Nilsson S, Mårdh PA. Bacterial vaginosis and smoking. Int J STD AIDS (2000) 11:603-6. doi: 10.1258/0956462001916461

100. Guaschino S, De Seta F, Piccoli M, Maso G, Alberico S. Aetiology of preterm labour: bacterial vaginosis. BJOG (2006) 113:46-51. doi: 10.1111/j.1471-0528.2006.01122.x

101. Luong ML, Libman M, Dahhou M, Chen MF, Kahn SR, Goulet $\mathrm{L}$, et al. Vaginal douching, bacterial vaginosis, and spontaneous preterm birth. J Obstet Gynaecol Can. (2010) 32:313-20. doi: 10.1016/S1701-2163(16)34474-7

102. Morison L, Ekpo G, West B, Demba E, Mayaud P, Coleman R, et al. Bacterial vaginosis in relation to menstrual cycle, menstrual protection method, and sexual intercourse in rural Gambian women. Sex Transm Infect. (2005) 81:242-7. doi: 10.1136/sti.2004.011684

103. Eschenbach DA, Thwin SS, Patton DL, Hooton TM, Stapleton AE, Agnew $\mathrm{K}$, et al. Influence of the normal menstrual cycle on vaginal tissue, discharge, and microflora. Clin Infect Dis. (2000) 30:901-7. doi: 10.1086/313818

104. Smart S, Singal A, Mindel A. Social and sexual risk factors for bacterial vaginosis. Sex Transm Infect. (2004) 80:58-62. doi: 10.1136/sti.2003.004978

105. Tolosa JE, Chaithongwongwatthana S, Daly S, Maw WW, Gaita $\mathrm{H}$, Lumbiganon $\mathrm{P}$, et al. The International infections in pregnancy study:variations in the prevalence of bacterial vaginosis and distribution of morphotypes in vaginal smears among pregnant women. Am J Obstet Gynecol. (2006) 195: 1198-204. doi: 10.1016/j.ajog.2006.08.016

106. Amabebe E. Analysis of Cervicovaginal Fluid Metabolome and Microbiome in Relation to Preterm Birth. Ph.D. thesis, White Rose eTheses Online: University of Sheffield (2016).

107. Khoo B, Boshier PR, Freethy A, Tharakan G, Saeed S, Hill N, et al. Redefining the stress cortisol response to surgery. Clin Endocrinol. (2017) 87:451-8. doi: $10.1111 /$ cen.13439

108. Plumpton FS, Besser GM. The adrenocortical response to surgery and insulin-induced hypoglycaemia in corticosteroid-treated and normal subjects. BJS (1969) 56:216-9. doi: 10.1002/bjs.1800560315

109. Jung C, Greco S, Nguyen HHT, Ho JT, Lewis JG, Torpy DJ, et al. Plasma, salivary and urinary cortisol levels following physiological and stress doses of hydrocortisone in normal volunteers. BMC Endocrine Disord. (2014) 14:91. doi: 10.1186/1472-6823-14-91

110. Shapiro GD, Fraser WD, Frasch MG, Séguin JR. Psychosocial stress in pregnancy and preterm birth: associations and mechanisms. J Perinat Med. (2013) 41:631-45. doi: 10.1515/jpm-2012-0295

111. Harville EW, Hatch MC, Zhang J. Perceived life stress and bacterial vaginosis. J Womens Health (2005) 14:627-33. doi: 10.1089/jwh.2005.14.627

112. Harville EW, Savitz DA, Dole N, Thorp JM Jr, Herring AH. Psychological and biological markers of stress and bacterial vaginosis in pregnant women. BJOG (2007) 114:216-23. doi: 10.1111/j.1471-0528.2006.01209.x

113. Ruiz RJ, Fullerton J, Brown CEL, Schoolfield J. Relationships of cortisol, perceived stress, genitourinary infections, and fetal fibronectin to gestational age at birth. Biol Res Nurs. (2001) 3:39-48. doi: 10.1177/109980040100300106

114. Jašarević E, Rodgers AB, Bale TL. A novel role for maternal stress and microbial transmission in early life programming and neurodevelopment. Neurobiol Stress (2015) 1:81-8. doi: 10.1016/j.ynstr.2014.10.005

115. Gupta K, Stapleton AE, Hooton TM, Roberts PL, Fennell CL, Stamm WE. Inverse association of $\mathrm{H}_{2} \mathrm{O}_{2}$-producing lactobacilli and vaginal Escherichia coli colonization in women with recurrent urinary tract infections. $J$ Infect Dis. (1998) 178:446-50.

116. Ehrström SM, Kornfeld D, Thuresson J, Rylander E. Signs of chronic stress in women with recurrent candida vulvovaginitis. Am J Obstet Gynecol. (2005) 193:1376-81. doi: 10.1016/j.ajog.2005.03.068

117. Sekirov I, Russell SL, Antunes LCM, Finlay BB. Gut microbiota in health and disease. Physiol Rev. (2010) 90:859-904. doi: 10.1152/physrev.00045.2009

118. Zijlmans MAC, Korpela K, Riksen-Walraven JM, de Vos WM, de Weerth C. Maternal prenatal stress is associated with the infant intestinal microbiota. Psychoneuroendocrinology (2015) 53:233-45. doi: 10.1016/j.psyneuen.2015.01.006

119. Beijers R, Buitelaar JK, de Weerth C. Mechanisms underlying the effects of prenatal psychosocial stress on child outcomes: beyond the HPA axis. Eur Child Adolesc Psychiatry (2014) 23:943-56. doi: 10.1007/s00787-014-0566-3

120. Bailey MT, Lubach GR, Coe CL. Prenatal stress alters bacterial colonization of the gut in infant monkeys. J Pediatr Gastroenterol Nutr. (2004) 38:414-21. doi: 10.1097/00005176-200404000-00009

121. Schiffrin EJ, Carter EA, Walker WA, Frieberg E, Benjamin J, Israel EJ. Influence of prenatal corticosteroids on bacterial colonization in the newborn rat. J Pediatr Gastroenterol Nutr. (1993) 17:271-5.

122. Wenzl HH, Schimpl G, Feierl G, Steinwender G. Effect of prenatal cortisone on spontaneous bacterial translocation from gastrointestinal tract in neonatal rat. Dig Dis Sci. (2003) 48:1171-6. doi: 10.1023/A:1023789301547

123. Shennan $\mathrm{AH}$, Chandiramani M. Antibiotics for spontaneous preterm birth. BMJ (2008) 337:a3015. doi: 10.1136/bmj.a3015

124. Al-Ghazzewi FH, Tester RF. Biotherapeutic agents and vaginal health. J Appl Microbiol. (2016) 121:18-27. doi: 10.1111/jam.13054

125. Reid G, Soboh F, Bruce AW, Mittelman M. Effect of nutrient composition on the in vitro growth of urogenital lactobacilli and uropathogens. Can J Microbiol. (1998) 44:866-71. doi: 10.1139/w98-068

126. Rousseau V, Lepargneur JP, Roques C, Remaud-Simeon M, Paul F. Prebiotic effects of oligosaccharides on selected vaginal lactobacilli and pathogenic microorganisms. Anaerobe (2005) 11:145-53. doi: 10.1016/j.anaerobe.2004.12.002

127. Hütt P, Lapp E, Štšepetova J, Smidt I, Taelma H, Borovkova N, et al. Characterisation of probiotic properties in human vaginal lactobacilli strains. Microb Ecology Health Dis. (2016) 27:30484. doi: 10.3402/mehd.v27.30484

128. Saduakhasova S, Kushugulova A, Shakhabayeva G, Kozhakhmetov S, Khasenbekova Z, Tynybayeva I, et al. Lactobacillus for vaginal microflora correction. Cent Asian J Glob Health (2014) 3(Suppl):171. doi: 10.5195/CAJGH.2014.171

129. Reid G. Probiotic and prebiotic applications for vaginal health. J AOAC Int. (2012) 95:31-4. doi: 10.5740/jaoacint.SGE_Reid

130. Tester R, Al-Ghazzewi FH. Intrinsic and extrinsic carbohydrates in the vagina: a short review on vaginal glycogen. Int J Biol Macromol. (2018) 112:203-6. doi: 10.1016/j.ijbiomac.2018.01.166

131. Lepargneur JP. Lactobacillus crispatus as biomarker of the healthy vaginal tract. Ann Biol Clin. (2016) 74:421-7. doi: 10.1684/abc.2016.1169

132. Otsuki K, Imai N. Effects of lactoferrin in 6 patients with refractory bacterial vaginosis. Biochem Cell Biol. (2016) 95:31-3. doi: 10.1139/bcb-2016-0051

133. Otsuki K, Tokunaka M, Oba T, Nakamura M, Shirato N, Okai T. Administration of oral and vaginal prebiotic lactoferrin for a woman with a refractory vaginitis recurring preterm delivery: appearance of lactobacillus in vaginal flora followed by term delivery. J Obstet Gynaecol Res. (2014) 40:583-5. doi: 10.1111/jog.12171

134. Giunta G, Giuffrida L, Mangano K, Fagone P, Cianci A. Influence of lactoferrin in preventing preterm delivery: a pilot study. Mol Med Rep. (2012) 5:162-6. doi: 10.3892/mmr.2011.584

135. Keelan JA. Pharmacological inhibition of inflammatory pathways for the prevention of preterm birth. J Reprod Immunol. (2011) 88:176-84. doi: 10.1016/j.jri.2010.11.003 
136. Schmitz T, Souil E, Herve R, Nicco C, Batteux F, Germain G, et al. PDE4 inhibition prevents preterm delivery induced by an intrauterine inflammation. J Immunol. (2007) 178:1115-21. doi: 10.4049/jimmunol.178. 2.1115

137. Mehats C, Schmitz T, Oger S, Herve R, Cabrol D, Leroy MJ. PDE4 as a target in preterm labour. BMC Pregnancy Childbirth (2007) 7(Suppl. 1):S12. doi: 10.1186/1471-2393-7S1-S12

138. Luppi P. How immune mechanisms are affected by pregnancy. Vaccine (2003) 21:3352-7. doi: 10.1016/S0264-410X(03)00331-1
Conflict of Interest Statement: The authors declare that the research was conducted in the absence of any commercial or financial relationships that could be construed as a potential conflict of interest.

Copyright (C) 2018 Amabebe and Anumba. This is an open-access article distributed under the terms of the Creative Commons Attribution License (CC BY). The use, distribution or reproduction in other forums is permitted, provided the original author(s) and the copyright owner(s) are credited and that the original publication in this journal is cited, in accordance with accepted academic practice. No use, distribution or reproduction is permitted which does not comply with these terms. 